\title{
Quantitative analysis of summer air masses in the eastern United States and an application to human mortality
}

\author{
J. Scott Greene ${ }^{1, *}$, Laurence S. Kalkstein ${ }^{2}$ \\ ${ }^{1}$ Oklahoma Climate Survey and Environmental Verification and Analysis Center, University of Oklahoma, \\ Norman, Oklahoma 73019, USA \\ ${ }^{2}$ Center for Climatic Research, University of Delaware, Newark, Delaware 19702, USA
}

\begin{abstract}
A recently developed continental-scale air mass-based classification is used to identify the spatial occurrences of 6 air masses (dry polar, dry temperate, dry tropical, moist polar, moist temperate, and moist tropical) in the eastern United States for summer from 1961 to 1990 . This procedure, the spatial synoptic classification (SSC), is based on 'seed' day identification of synoptic events and discriminant analysis to group days together which are within the same air mass type. Thus, the evaluation of the frequency and modification of air masses across a large region is possible. Using the SSC, maps of air mass frequencies and afternoon temperatures and dew points are developed. Rates of modification are determined as each air mass traverses the region. As an example of the environmental applicability of the SSC, the impact of climate upon human mortality is analyzed at 3 climatically different locations (New Orleans, LA; Memphis, TN; and Chicago, IL). Results show how the day-to-day mortality fluctuations are sensitive to air mass type. A particular air mass which is associated with distinctly high mortality is identified for Memphis and Chicago; no such air mass is apparent for New Orleans, where the weather/mortality signal is very weak.
\end{abstract}

KEY WORDS: Synoptic climatology $\cdot$ Weather/health relationships $\cdot$ Air masses

\section{INTRODUCTION}

The use of synoptic climatological classifications by researchers from a variety of disciplines has increased considerably over the past 20 yr. Over this time, significant progress has been made in increasing the sophistication of synoptic climatological approaches to evaluate climate/environmental problems (Yarnal 1993). A synoptic categorization can be of considerable utility to the applied researcher as it produces meteorologically homogeneous groups of events which can be used to evaluate the potential synergistic impacts of an entire suite of weather elements on an environmental parameter sensitive to weather (Barry \& Perry 1973). The

•E-mail: jgreene@uoknor.edu types of synoptic events identified by existing classifications can be loosely described as either 'weather types' or 'air masses'. Weather types are synoptic events categorized by pressure patterns and wind fields, while an air mass is a large volume of air '...acquiring characteristics of temperature and humidity related to the condition of the sea, land or ice beneath it' (Crowe 1971).

Weather type classifications are effective in studies which analyze atmospheric transport mechanisms. For example, pollution dispersal and atmosphericallyforced insect migration patterns have been conveniently analyzed using weather typing approaches (Muller \& Jackson 1985). There have also been a wide number of circulation-based synoptic classifications developed in Europe (e.g. Bauer et al. 1944) to examine such diverse applied climate topics as detection of 
climate change (Bardossy \& Caspary 1990) and river water quality and air quality (Wilby 1993). Refer to Yarnal (1993) or El-Kadi \& Smithson (1992) for a more complete discussion of various synoptic and circulation-based classifications.

Weather type classifications are less useful in studies where thermodynamically homogeneous groupings are required. If circulation characteristics are comparable on different days, it is probable that the thermal and moisture characteristics of these days would also be similar; however, there are notable exceptions. For example, consider an anticyclone located over the Great Plains in summer. This system would be supported by negative vorticity advection aloft, and could result in a variety of distinct meteorological conditions at the surface. One would be cool, dry air which has been transported into the region from Canada. Under these conditions, skies would be clear with afternoon temperatures below $25^{\circ} \mathrm{C}$. Another situation might be modified Pacific air, which is warmed adiabatically on the lee side of the Rockies, resulting in afternoon temperatures around $30^{\circ} \mathrm{C}$ in this area. An additional possibility is the intrusion of dry, warm air from the Desert Southwest, which would result in afternoon temperatures above $35^{\circ} \mathrm{C}$. Thus, for applications where the thermal and moisture characteristics of the air are especially important, weather typing may be less desirable because of this meteorological heterogeneity.

Air mass approaches typically classify days based on a wider variety of weather elements, such as cloud cover, visibility, and precipitation, as well as various thermal and atmospheric moisture variables. Therefore, these classifications are distinctly less dependent upon pressure patterns and wind fields. The classic description of an air mass as defined by Bergeron (1930) identified polar, tropical, continental, and maritime air masses according to their source regions. However, the goal of this study is to characterize the different air masses based upon differences in thermodynamic character, as environmental responses to air masses are dependent on the meteorological character of the air at a given place at a given time. Thus, source region determination is not as important as the identification of 'umbrellas of air' which traverse a region and possess distinctive meteorological characteristics. The criteria of the Spatial Synoptic Classification (SSC) described here are used to categorize thermal and moisture variables, which ultimately influence the behavior of a variety of environmental parameters

Some synoptic classifications have been used as point indices, such as the weather-typing approach adopted by Muller (1977), or the Temporal Synoptic Index (TSI) (Kalkstein et al. 1987). These indices have proven useful in examining a range of environmental variables. However, expanding either of these point indices would be time-consuming and unmanageable from an analytical standpoint (Kalkstein et al. 1996). On a larger scale, several regional approaches have described weather types or air masses across an area of several thousand $\mathrm{km}^{2}$. For example, Schwartz (1991) evaluated July air mass frequencies at 15 sites in the north central U.S. He successfully identified 5 air masses by incorporating the 'partial collective' method developed by Bryson (1966). While numerous point and regional classifications have been accurately used to identify weather types and air masses, continentalscale air mass classifications have been more difficult to devise. Davis \& Kalkstein (1990) applied procedures similar to those of the TSI to develop a continentalscale classification (over the contiguous U.S.) for 1984. This classification was used to analyze air quality variations; however, the procedure suffers from important shortcomings. First, the technique must be developed on a day-to-day basis, which can be exceedingly timeconsuming when treating a dataset of many years. Second, there were considerable problems tracking a given air mass across the country, especially if modification occurred during transport. Third, the procedure produced far too many synoptic types, which varied both seasonally and regionally, to be practical.

Despite recent advances in the classification of synoptic-scale events, particularly at the point and regional scales, there remains the need for development of a simpler, automated, large-scale air massbased procedure. A new method of analysis to identify resident air masses on a national scale has recently been developed (Greene 1994, Kalkstein et al. 1996). This procedure is less complex than previous classifications, yet permits inter-site comparison of daily air masses across a large region. The resulting spatial air mass inventory could have important environmental applications, such as the determination of climatic limiting factors for certain biotic communities, the impact of temporary surface features, such as snow, on air mass modification rates, and an evaluation of precipitation characteristics for individual air masses. This paper will describe results derived from an air mass classification performed at 126 first-order weather stations east of the Rocky Mountains during a 30 yr period (1961 through 1990) for summer (June, July, and August), and give an illustrative example of the classification's usefulness in analyzing environmental problems. Although discussion is largely confined to summer, the procedure is designed to classify air masses year-round, and cursory winter analyses have already been developed (Kalkstein et al. 1996). The evaluation here is confined to the less complex terrain east of the Rockies, where spatial patterns of air mass frequency and character are easier to discern 


\section{METHODS}

2.1. Air mass identification. Unlike existing classification techniques, the SSC requires initial identification of the meteorological characteristics of typical synoptic conditions at each station. The term air mass is used here to indicate homogeneous, holistic weather categories based on meteorological characteristics. Initially, the 4 categories frequently delineated as air masses (mT, Maritime Tropical; mP, Maritime Polar cT, Continental Tropical; and cP, Continental Polar) were used. However, a cluster analysis of meteorological data for a sample of stations and a detailed map analysis determined these types as too restrictive, and not fully reflective of existing conditions. For example, air from the Pacific is strongly modified when traversing the western mountain systems, and takes on a character quite different from its origin. This 'Pacific' air ultimately possesses distinct continental characteristics when it descends the lee of the Rockies, but it is unlike $\mathrm{cP}$ or $\mathrm{CT}$. Similarly, the surface air mass expression associated with frequent overrunning conditions is not represented in the traditional Bergeron (1930) model. Thus, the historical weather map and cluster analysis suggested that 6 air mass types are commonly present in the contiguous United States, and can be categorized daily. The SSC identifies the following air mass types over the eastern United States:

(1) Dry Polar (DP)

(4) Moist Polar (MP)

(2) Dry Temperate (DM) (5) Moist Temperate (MM)

(3) Dry Tropical (DT)

(6) Moist Tropical (MT)

The above nomenclature is different from existing thermodynamically-based synoptic categories, as it places an emphasis on the character, rather than the source region, of the air mass. The physical character of the 6 air masses in summer can be described as follows.

Dry Polar (loosely synonymous with continental polar) is relatively cool and dry, with generally clear skies and little chance of convective precipitation. High pressure, typically found within an anticyclone of Canadian origin, is most frequently associated with Dry Polar air.

Dry Temperate air is generally associated with zonal flow aloft, which permits moist Pacific Ocean air to dry adiabatically as it descends the Rockies. This air mass brings mild, dry conditions to the midwestern and eastern United States due to adiabatic warming, and is analogous to Pacific air identified by Schwartz (1991) and others. In the southeastern United States, this air mass can also be produced when polar air is transported around a surface anticyclone and modified by a long trajectory over the Atlantic Ocean. This subset of Dry Temperate air has been identified as 'East Coast' air by Kalkstein (1972).
Dry Tropical air is often associated with the hottest and driest conditions, as well as clear skies. It typically originates in the Desert Southwest or northern Mexico, and frequently intrudes into the southern Plains around the western edge of an anticyclone. In addition to dry desert air advected from the Southwest, this air mass includes chinook events in the northwestern portions of the study region. The violent, dry downsloping of chinooks produces conditions that, at the surface, are similar to desert air. Hence, areas of northern Colorado and Wyoming can occasionally experience as much Dry Tropical air as western Texas, even during summer.

Moist Polar air is associated with generally overcast conditions, cool temperatures, a small dew point depression and, frequently, easterly flow at the surface. This can occur when a front is located well to the south, producing an overrunning situation. However, in the eastern portion of the study region, Moist Polar is often advected from the Atlantic around the northern flank of a mid-latitude cyclone. Both of these processes result in virtually identical surface expressions; thus, these conditions are grouped together

Moist Temperate can also be associated with frontal activity, and is thus characterized by many of the same elements as Moist Polar. However, the temperature and dew point are considerably higher for Moist Temperate, and the responsible front is typically located much closer to the region. Both Moist Polar and Moist Temperate conditions can persist for some time if a quasi-stationary front is located nearby.

Moist Tropical air, commonly recognized as maritime tropical, is warm and moist, as it generally originates from the Gulf of Mexico or tropical oceans. This air is found in the warm sector of a mid-latitude cyclone, or on the western flank of a subtropical anticyclone. Of the 6 types, convective activity is most common to this air mass, particularly during summer (Greene 1994).

2.2. The Spatial Synoptic Classification. The SSC was developed to classify all days within one of these predetermined, readily identifiable, air mass categories. Each day is classified using 'seed days' and linear discriminant function analysis. What follows is a brief description of the procedure (for greater detail, refer to Kalkstein et al. 1996 or Greene 1994).

The procedure relies on the input of groups of 'seed days' for each air mass at each locale (Fig. 1; from Kalkstein et al. 1996). Seed days represent days possessing the typical meteorological character of each air mass at a location and are used to classify all other days. Each group of seeds is chosen by the specification of ranges in afternoon surface temperature, dew point, dew point depression, wind speed, wind direction, cloud cover, diurnal temperature change, and 4 six-hourly dew point changes. Afternoon meteorological observations are most useful for selecting seed days 


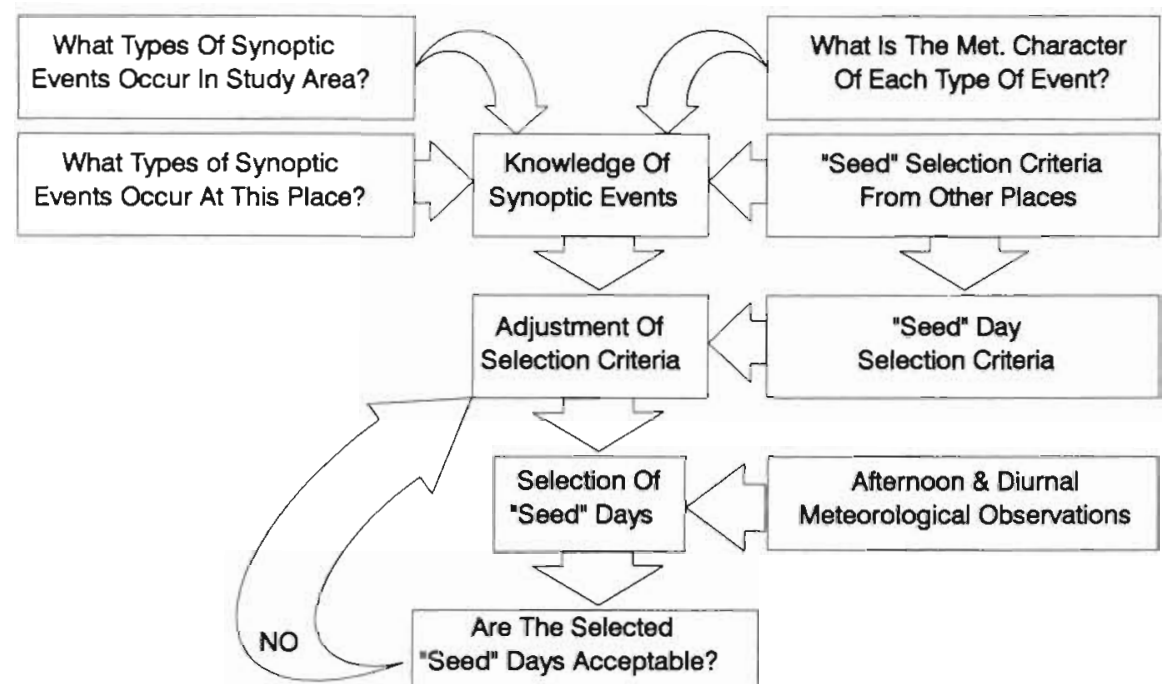

Fig. 1. Procedure to select seed days which represent 'pure' synoptic events

because it is at this time that air masses are most physically distinct from one another. Narrow ranges in 5 trend variables are used to prevent those days which have undergone significant changes (such as frontal passages which represent air mass transition days) from being selected as seed days. Initial estimates of these criteria are specified for each air mass at each location after careful evaluation of surface meteorological data and maps, and days which satisfy them are selected to represent that air mass. The criteria are then iteratively adjusted until all seeds selected comprise a homogeneous representation of the air mass.

Following seed day selection, discriminant function analysis is used to generate a linear function for each air mass from its group of seed days. Since the goal is to classify each day into one of the pre-existing air masses described above, and to use the seed day means as input into the classification, discriminant function analysis was selected as the appropriate classification tool (Klecka 1980, James 1985). Discriminant analysis is similar to multiple regression. For each air mass type, a discriminant function is developed based upon the means of the seed day groups. Each day in the period of record is subsequently evaluated using all air mass discriminant functions to determine which group it most closely resembles. The day is classified into the category possessing the highest score. The result of this evaluation is a calendar listing the air mass to which each day has been assigned.

While a majority of these air mass designations are correct, a significant number of days may be incorrectly classified because they represent a transition between air masses. To account for this possibility, the SSC performs a second discriminant function analysis to determine whether a transition between air masses occurred during each day. Two groups of seed days are used for this analysis: the group of seed days representing transitions between air masses (these contain substantial trends in meteorological character through the day), and a group containing the combined seed days of all air masses at that location. This discriminant analysis produces a second calendar which designates each day as either transitional or non-transitional. All days classified as non-transitional are placed into the category assigned them by the initial discriminant analysis. All other days are classified as transitions.

\section{RESULTS}

The above procedure produces a calendar of summer daily air mass occurrences for 126 first-order weather stations east of the Rocky Mountains (winter categorization for these stations is described in Kalkstein et al. 1996). Using this calendar and the hourly data for each location, the SSC computes means, maxima, minima, and standard deviations for each meteorological element to identify the comparative character of each air mass.

\subsection{Summer air mass frequencies}

Using the SSC, days were classified into 1 of the 6 air masses described above, and air mass frequencies over summer were examined (Fig. 2). The least frequently occurring air mass in the summer is DP (Fig. 2a). The frequencies range from over $15 \%$ in northern Minnesota and North Dakota, to less than $1 \%$ along the Gulf Coast. DP air never occurred in southern Florida 

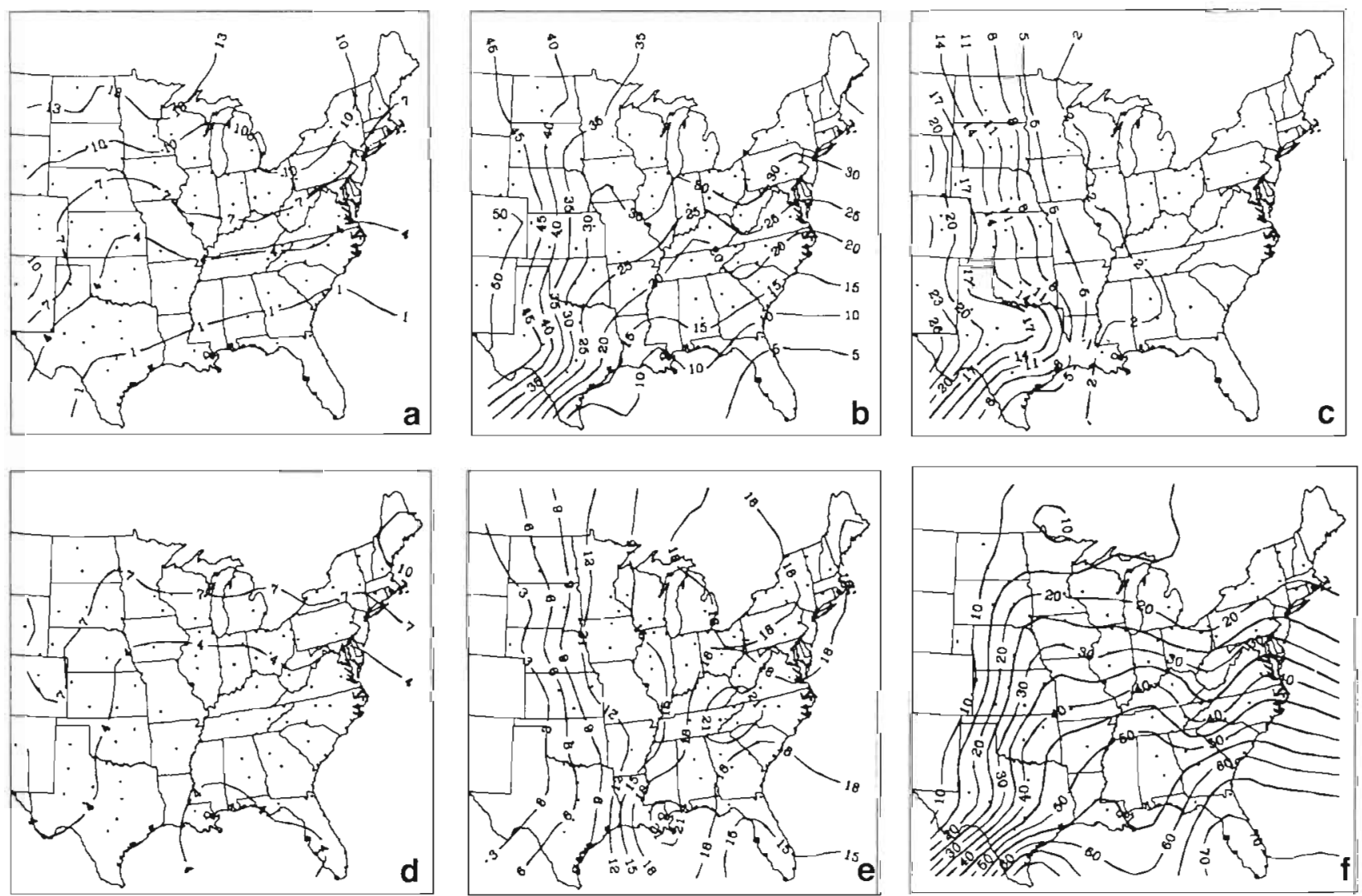

Fig. 2. Air mass frequencies (percent for 1961 to 1990). (a) Dry Polar; (b) Dry Temperate; (c) Dry Tropical; (d) Moist Polar; (e) Moist Temperate; (f) Moist Tropical. Points on the map represent all stations where a particular air mass was detected during the study period

during the period of study. These values offer an interesting contrast to DP winter frequencies (December, January, and February) using SSC (Kalkstein et al. 1996). Winter frequencies in the north were at least twice as high, approaching $30 \%$ in the extreme north central and northeastern U.S. The proportional disparity between summer and winter frequencies is even greater toward the Gulf Coast, where DP occurred about $10 \%$ of the time in winter. The dramatic differences in the gradient of DP air between summer and winter can be partially explained by seasonal variation in the circumpolar vortex. In winter, frequent East Pacific ridging increases the northerly component of the mid-tropospheric height contours, and allows for the related movement of Arctic air masses southeast into central North America. During summer, however, there is a minimum in the tropospheric height gradient, which results in a decrease in the areal extent of the westerlies. This effectively inhibits significant southeastern movement of polar air (Harmon 1991).

The other 2 dry air masses have a more significant presence during summer. In the East, DM air exhibits a north-south decrease in frequency, ranging from about $30 \%$ in New England to about $5 \%$ in southern Florida (Fig. 2b). Trends were somewhat the opposite during winter, where the greatest frequencies of dry temperate air along the East Coast were found in Georgia and South Carolina. Toward the western boundary of the study region, the summer frequency pattern shifts, and there is a more pronounced westeast frequency distribution over the Great Plains. Much of the DM air originates from the Pacific, and moves east when the upper-level circulation exhibits a zonal pattern, or a slight ridge over the Rocky mountains. Eastward of this ridge, there is mid-level subsidence (Borchert 1950, Corcoran 1982). This enhances the warm stable condition on the lee side of the Rockies. This pattern occurs regularly in the summer; consequently, the highest frequency of DM air is just to the lee of the Rocky Mountains, with values near $50 \%$ in eastern Colorado and Wyoming. There is a similar winter DM pattern in this region, although summer frequencies are generally higher, especially over the Northern Plains. 
Not surprisingly, DT frequencies decrease markedly away from the Desert Southwest (Fig. 2c). Unlike the other air masses, there is a consistent west-east decrease in frequency across the study area. The values range from $25 \%$ in western Texas to near zero in the Southeast. Although infrequent throughout the eastern U.S., there are a few incursions of the air mass in the Northeast, usually around the northern flank of a deep ridge when it was centered over the Southeast. Many of the stations in the Northeast (e.g. New York, Philadelphia) exhibit a small frequency of DT (less than $1 \%$ ), but only during extreme summers such as 1988 and 1995. This never occurs in the Southeast, where the deep ridge prevents the incursion of hot, dry desert air. In addition to dry desert air advected from the Southwest, this air mass encompasses chinook events in the northwestern portions of the study region. Chinooks are common during periods of strong upper-level westerlies. Over the Rockies, an area of negative vorticity advection will develop, allowing for subsidence and downsloping of air (Borchert 1950); this, combined with the strong surface winds, produces chinook situations. These violent, dry downsloping conditions are, at the surface, almost indistinguishable from desert air. Hence, areas of northern Colorado and Wyoming exhibit DT frequencies of about $20 \%$ during summer. Winter DT frequencies are much less, and only exceed $10 \%$ in western Texas.

MP is relatively rare in summer, and increases slightly toward the north (Fig. 2d). While most of the days associated with frontal conditions in the summer are classified as MM, a few of the coolest days (often associated with the strongest anticyclones) are classified as MP. This air mass probably exhibits the greatest frequency differential between seasons. MP frequencies are over $40 \%$ during winter in a large area from western New York to eastern Wisconsin, and over 30\% in much of the northern third of the country. This contrasts strongly to the 4 to $7 \%$ frequency of this air mass over the same region in summer.

MM is also not predominant in summer, but does occur at frequencies of 15 to $20 \%$ across much of the U.S. east of the Mississippi River (Fig. 2e). There is a steep decline in the frequency of this air mass across Texas due to the dominance of dry DT and DM air in this area, and no MM air was found in western Texas or in eastern Colorado. In winter, the frequency maximum for MM is along the Gulf Coast (Kalkstein et al. 1996), where stationary fronts often align. Under these conditions, frontal overrunning, which is associated with overcast conditions and precipitation, occurs frequently (Hsu 1988). In the summer, however, the maximum shifts north into Tennessee, southwestern Virginia, and western North Carolina. Some of this might be orographic, as increases in cloud cover along the western flank of the Appalachians during southwesterly flow situations might lower temperatures and decrease diurnal range. Convective activity maxima (and concurrent cloud cover) around the central Gulf Coast might also be responsible for the higher MM frequencies from Baton Rouge to Mobile.

The most dominant air mass in summer, particularly in the southeastern United States, is MT (Fig. 2f). Perhaps the most dramatic feature of this air mass is the sharp decrease in frequency across Texas, which is associated with a concomitant increase of dry air from the Desert Southwest. Occurrences of MT range from over 2 out of 3 days from Corpus Christi to Brownsville to zero in El Paso. The entire Southeast is dominated by this air mass, with maximum frequencies found over the Florida peninsula. The frequencies decrease toward the north, and less than $20 \%$ of the days are classified as MT north of a line from Boston to Detroit to Minneapolis. Although frequency orientations are similar in winter, actual values are obviously much less. The winter $20 \%$ frequency line roughly parallels the Gulf Coast. The gradient along the eastern coast is partially the result of the north-south migration of the Bermuda high during the summer (Harmon 1987). The MT frequency pattern along the western Gulf of Mexico in the summer is associated with the interaction of a surface pressure gradient between the Bermuda high and the thermally-induced low pressure over the southwestern U.S. As a result, the mean surface movement of MT is northward from the Gulf of Mexico (Wendland \& Bryson 1981). The strong gradient in MT across western Texas can be attributed to mid-level subsidence over the central states which acts to inhibit convection during MT intrusions, and to dilute the northward flowing MT with drier, mid-level air (Corcoran 1982).

\subsection{Summer air mass character}

The temperature gradients of DP and DM show a general north-south orientation (Fig. $3 a$, b), with a slight dip along the western edge of the Appalachians in western Pennsylvania and West Virginia. The highest temperatures for both air masses are found in Texas, and drier conditions in the Great Plains seem to contribute to higher maximums than further east. The summer temperature gradient for both air masses is much weaker than for winter. For example, DP mean afternoon temperatures increase by over $24^{\circ} \mathrm{C}$ from northern Minnesota to southern Texas in winter (Kalkstein et al. 1996). This value is about $8^{\circ} \mathrm{C}$ in summer DM maximum temperatures vary even less spatially; there is only about a $6^{\circ} \mathrm{C}$ differential between highest and lowest values throughout the study region. The 

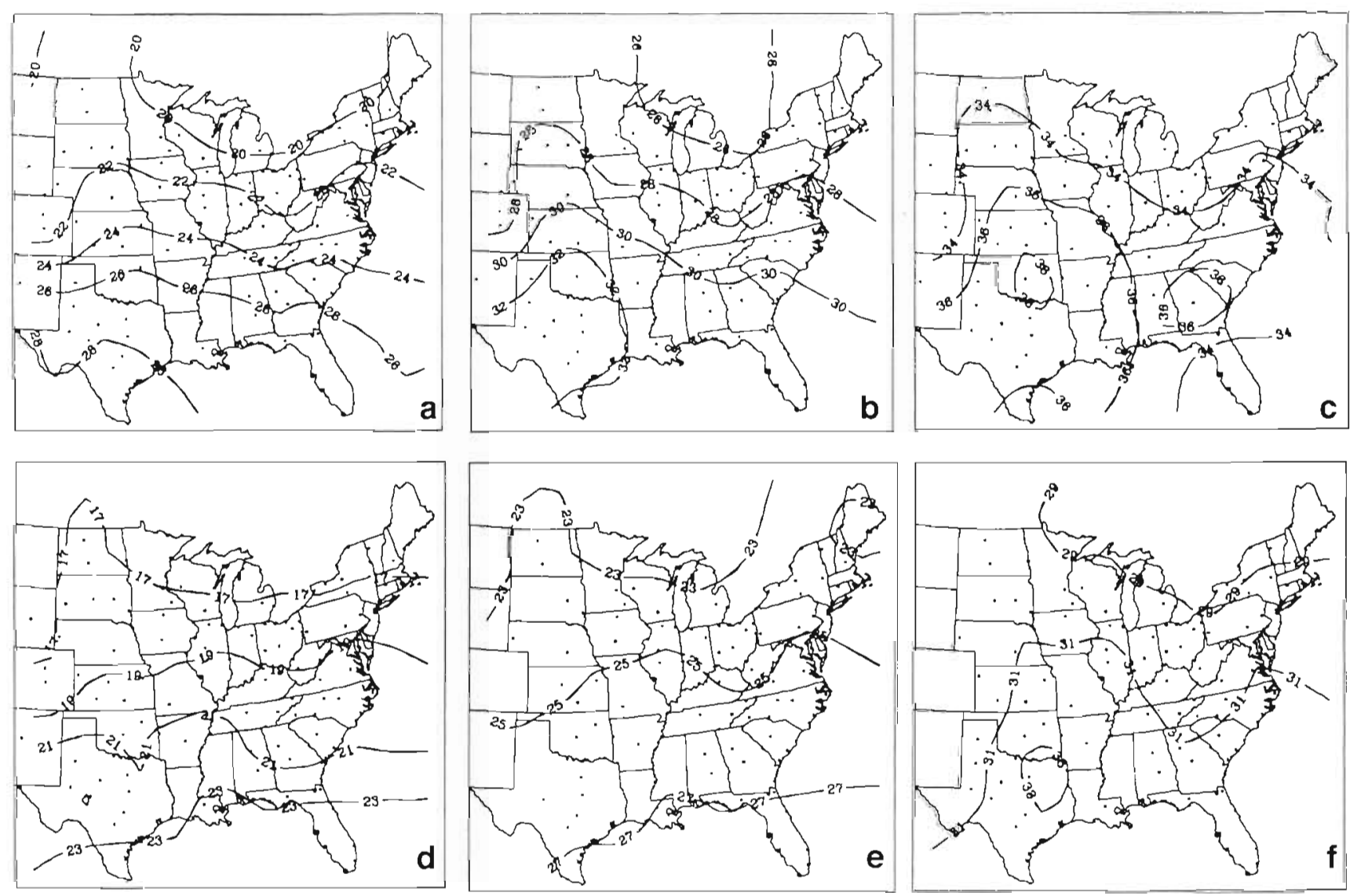

Fig. 3. Mean 15:00 h LST (Local Standard Time) temperature $\left({ }^{\circ} \mathrm{C}\right.$ ). (a) Dry Polar; (b) Dry Temperate; (c) Dry Tropical; (d) Moist Polar; (e) Moist Temperate; (f) Moist Tropical. Points on the map represent all stations where a particular air mass was detected during the study period

decreased temperature gradient can be explained by the changes in the daylength from summer to winter In winter, there is a wide difference in the duration of sunlight and solar intensity from the northern plains to the Gulf Coast. However, in summer, incoming solar radiation, and the associated temperature gradient, are less steep, due to increasing daylength to the north.

The thermal character of DT exhibits only slight modification as it traverses the region in summer (Fig. 3c). Afternoon temperatures range from near $40^{\circ} \mathrm{C}$ in southwestern Texas and Oklahoma to $35^{\circ} \mathrm{C}$ in the Northeast. The pattern shows a southwest-northeast trend, suggesting the direction of modification as the air flows out of the southwestern deserts. The particularly high temperatures in central Oklahoma are noteworthy; it confirms previous research indicating that this area possesses the most sultry summer climate in the United States because of unusually high apparent temperatures when DT and MT air masses are present (Kalkstein \& Valimont 1986).

The moist air masses display even smaller temperature gradients in summer, owing to their higher specific heat (Fig. 3d, e, f). During summer, the coolest air mass is actually MP, with average afternoon temperatures remaining below $20^{\circ} \mathrm{C}$ in the northern half of the study region. The MM and MT air masses have particularly small thermal gradients; the difference in mean afternoon temperature for both between Georgia and New York is only $2^{\circ} \mathrm{C}$. Thus, these air masses barely modify as they traverse great distances in summer.

Dew point gradients are somewhat similar to temperature gradients for all 6 air masses, with a few interesting exceptions (Fig. 4a-f). For example, afternoon dew point gradients for the 3 dry air masses have a more meridional component than do temperature gradients. This is especially true for the DT air mass, where very low dew points are noted in the western portions of the study region. Thus, some significant modification takes place as this air mass approaches the eastern U.S. The moist air masses do not exhibit this pattern, and although some modification of MP is apparent, the gradient is north-south. MT shows a particularly small gradient; mean dew points vary by only about $5^{\circ} \mathrm{C}$ throughout the area.

The distinct hydrodynamic patterns displayed by the air masses are related primarily to the surfaces they 

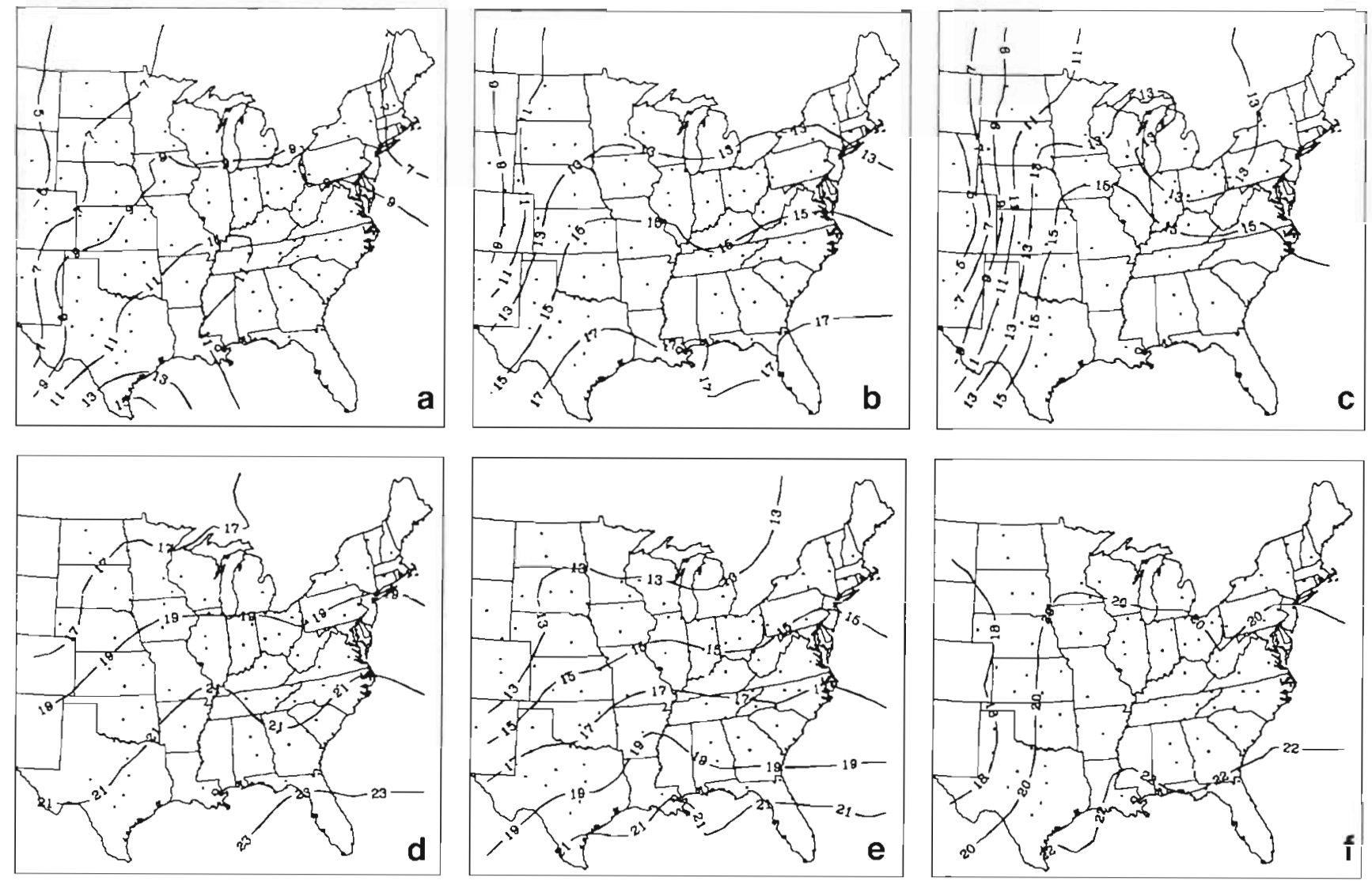

Fig. 4. Mean 15:00 h LST dew point $\left({ }^{\circ} \mathrm{C}\right.$ ). (a) Dry Polar; (b) Dry Temperate; (c) Dry Tropical; (d) Moist Polar; (e) Moist Temperate; (f) Moist Tropical. Points on the map represent all stations where a particular air mass was detected during the study period

must traverse during transport. For example, the relatively large west-east dew point gradient of DT is the result of a moist, vegetated cover that exists as the air mass moves eastward. This also explains the very small modification of the other air masses, as the generally homogeneous surface creates little opportunity for change. Of course, this is very different in winter, when surface conditions vary considerably, especially from north to south. Snow cover has been shown to be a major contributor to winter air mass modification rates (Kalkstein et al. 1996). In addition, significant latitudinal variations in solar radiation contribute to increased modification rates in winter.

\subsection{Potential application: weather-related mortality}

The summer of 1995 is an example of the potential impact of weather on human health, particularly acute mortality. The most notable case is Chicago, where over 500 perished from heat-related causes (CDC 1995). Deaths due to excessive heat were also reported in numerous U.S. cities, and across Europe (Kalkstein
1995). While the definition of heat-related death varies from place to place, variations in heat-related mortality are also due to the dissimilar responses to similar weather patterns at different locations.

People respond to the total effect of all weather variables interacting simultaneously on the body. Therefore, an appropriate means to evaluate weather/health relationships is through the identification of high risk air masses that, when present, could negatively affect human health. Studies funded by the U.S. Environmental Protection Agency (EPA) and the Southern and Southeast Regional Climate Centers show very strong relationships between certain very hot, oppressive air masses and increased human mortality. For example, Kalkstein (1991) has shown that, for many cities, it is apparent that one or two hot air masses possess a much higher mean mortality than the others, and these high risk air masses contain an inordinately high percentage of days with the greatest mortality totals. However, the use of the site-specific TSI prohibited a comparison of the impacts of the same air masses at different cities. The SSC provides a unique ability to identify similar air masses across continent-sized regions. Thus, it is 
now possible to determine if human response to particular air masses is similar in differing climates. To illustrate this point, we examined daily acute mortality at 3 climatologically distinct cities to determine if regional differences exist during similar weather conditions. New Orleans, Memphis, and Chicago were chosen to represent a cross section of large metropolitan areas with different climates. The mortality data for the Standard Metropolitan Statistical Areas (SMSAs) of these cities were obtained from the National Center for Health Statistics (NCHS), and contain information on cause, place and date of death, age, and race of every individual who has died in the United States from 1964 to present (NCHS 1978). All mortality data were adjusted to account for changes in the total population of the SMSA during the period of record. A direct standardization procedure was used, and a mortality trend line was constructed for the period of record based on mean daily mortality for each year of record. Mortality was then expressed as a deviation around the temporal baseline level (Kalkstein 1991).

The mean daily mortality for each synoptic category at each city, along with the standard deviation, was determined to ascertain whether particular categories exhibited distinctively high or low mortality values (Table 1). Potential lag times were accounted for by evaluating the daily synoptic category on the day of the deaths, as well as 1,2 , and $3 \mathrm{~d}$ before the day of the deaths. Daily mortality was also sorted from highest to lowest during the period of record to determine whether certain synoptic categories were prevalent during the highest and lowest mortality days for each of the cities. Results show that strong regional differences do, in fact, exist. In New Orleans, no air mass seems to be associated with particularly high mean daily mortality totals. However, Dry Tropical air has a

Table 1. Mortality means and standard deviations for the air masses. There is a $1 \mathrm{~d}$ lag between air mass type and mortality response

\begin{tabular}{|lrrr|}
\hline & $\begin{array}{c}\text { New Orleans } \\
\text { Mean }^{\mathrm{a}} \text { (SD) }\end{array}$ & $\begin{array}{r}\text { Memphis } \\
\text { Mean }^{\mathrm{d}} \text { (SD) }\end{array}$ & $\begin{array}{r}\text { Chicago } \\
\text { Mean }^{\mathrm{a}} \text { (SD) }\end{array}$ \\
\hline Dry Polar & $-0.26(2.28)$ & $-0.97(4.72)$ & $-2.00(8.41)$ \\
Dry Temperate & $-0.28(5.41)$ & $-0.42(4.84)$ & $-1.23(8.85)$ \\
Dry Tropical & $\mathrm{NP}^{\mathrm{b}}$ & $3.38(8.36)$ & $3.73(9.51)$ \\
Moist Polar & $-0.35(5.17)$ & $-1.41(4.21)$ & $-2.01(8.19)$ \\
Moist Temperate & $-1.12(5.81)$ & $-0.80(4.27)$ & $0.56(10.6)$ \\
Moist Tropical & $0.56(5.61)$ & $0.33(5.05)$ & $2.43(9.63)$ \\
a Values represent deviation from long term mean, and have \\
been adjusted for population changes through the period of \\
record \\
bry Tropical was not present at New Orleans during \\
period of study
\end{tabular}

statistically significant impact on mortality at Memphis and Chicago. In addition, the Moist Tropical air mass in Chicago also contributes to elevated mortality. These results are consistent with other studies that suggest increased mortality sensitivity to weather in climates with great summer weather variations (IPCC 1996, McMichael et al. 1996). However, this study is the first that permits direct comparison of similar air masses in different climates.

While some air masses possess a mean mortality well above the overall mean, not all days within this air mass type possess elevated mortality totals. Thus, it is important to not only identify the 'high risk' air mass, but to determine the important variables within each air mass that will result in elevated mortality on certain days (Table 2). A regression procedure was employed to determine those parameters within the air mass which contribute to the highest daily mortality. Independent variables included meteorological (e.g. maximum temperature, cloud cover) and non-meteorological (e.g. number of consecutive days of the air mass, time of season) variables which may impact mortality (refer to McMichael et al. 1996 for a more detailed explanation of the regression procedure). In Chicago, the factors that contribute to high daily mortality when the DT air mass is present include the number of consecutive DT days and maximum temperature. Thus, for each consecutive DT day, mortality increases in Chicago by an average of 2.41 deaths per day. At Memphis, maximum temperature is the only statistically significant independent variable which explains variation in mortality during DT occurrences. For each $1^{\circ} \mathrm{C}$ increase in maximum temperature, mortality increases in Memphis by an average of 1.94 deaths per day. The resulting algo-

Table 2. Results of regression analysis for high risk air masses

\begin{tabular}{|c|c|c|c|}
\hline Variable $^{d}$ & $\begin{array}{l}\text { Parameter } \\
\text { estimate }\end{array}$ & $\begin{array}{l}\text { Standard } \\
\text { error }\end{array}$ & $\mathrm{R}^{2} \mathrm{~b}$ \\
\hline \multicolumn{4}{|l|}{ Chicago } \\
\hline Intercept & -121.93 & & \\
\hline Consecutive day ${ }^{c}$ & 2.41 & 0.70 & \\
\hline Maximum temperature $\left({ }^{\circ} \mathrm{C}\right)$ & 2.39 & 0.64 & \\
\hline Total model & & & 0.31 \\
\hline \multicolumn{4}{|l|}{ Memphis } \\
\hline Intercept & -103.70 & & \\
\hline Maximum temperature $\left({ }^{\circ} \mathrm{C}\right)$ & 1.94 & 0.50 & \\
\hline Total model & & & 0.30 \\
\hline \multicolumn{4}{|c|}{$\begin{array}{l}\text { 'All variables are statistically significant at the } 0.05 \text { level } \\
\text { or better }\end{array}$} \\
\hline \multicolumn{4}{|c|}{$\begin{array}{l}{ }^{\mathrm{b}} \mathrm{R}^{2} \text { values have been adjusted for degrees of freedom in } \\
\text { the model }\end{array}$} \\
\hline \multicolumn{4}{|c|}{$\begin{array}{l}\text { "This variable evaluates the number of consecutive days } \\
\text { within the high-risk air mass }\end{array}$} \\
\hline
\end{tabular}


rithms satisfy the Box \& Wetz (1973) criteria as statistically robust predictors, and can be used to estimate mortality for any given day within the high risk air mass provided that the meteorological data are available.

It is clearly apparent that regional differences exist in the mortality/weather relationship. The same air mass can induce different human responses at different locales. Although MT air masses are associated with elevated mortality in Chicago, where it occurs on about $25 \%$ of the days in an average summer, this air mass has little impact on the population in Memphis or New Orleans, where it occurs much more often. This difference is noted in spite of the fact that the air mass has similar characteristics at all 3 cities. Thus, the response of mortality to air mass type described here represents an example of the relative impact of weather on human well-being. Of the 3 evaluated cities, Moist Tropical air represents a stressful conditıon in Chicago, where it occurs less frequenily. How ever, it produces little response in the southern cities where it occurs more often, and where some form of acclimatization is evident (Kalkstein 1991).

\section{CONCLUSIONS}

The SSC was created and used to develop an air mass climatology for the summer over the eastern U.S The SSC was designed to overcome limitations of existing air mass classifications such as the TSI; the site-specific nature of the TSI renders air mass comparisons difficult across space. The SSC is computationally simpler and is capable of identifying similar air masses across a large region.

The SSC was used to identify occurrences of 6 air masses at 126 locations east of the Rocky Mountains for summer, 1961 to 1990. The results indicate that the air mass patterns identified by the SSC were both spatially and temporally consistent across the study region. The maps of air mass frequencies and afternoon temperatures and dew points illustrate the common trajectories and modification rates of each air mass

The spatial and temporal consistency of the SSC make it applicable to environmental analyses, such as weather-health evaluations. The brief example shown here illustrates the inter-regional differences in human response to weather, and for the first time, permits impacts analysis of particular air masses across large regions. A more intensive study examining the summer mortality for 44 cities in the U.S. using SSC is currently under way.

Other health-related problems which are affected by atmospheric phenomena, such as asthma and allergy distress, are also well-suited to SSC analysis. Certain air mass types are associated with high concentrations of air pollutants, such as total suspended particulates and sulfates. With the availability of EPA-monitored air pollution data from numerous sites around the U.S., the SSC will permit continental-scale analyses of air masses which are responsible for increased asthma symptoms, and allow for the evaluation of weather/air pollution synergism on this and other health problems.

Acknowledgements. The support of the NASA Global Change Program (1776-GC-93-0133), the NOAA Office of Global Programs (NA37RJ0203) and the EPA Climate Change Division (CR-824404) is greatly appreciated. Thanks are also due to David Barthel and Michael Nichols for helping to develop SSC, and to Shouquan Cheng and Dan Graybeal for assistance in the mortality analysis.

\section{LITERATURE CITED}

Bardossy A, Caspary H (1990) Detection of climate change in Europe by analyzing atmospheric circulation patterns from 1881 to 1989. Theor Appl Climatol 42:157-167

Barry RG, Perry AH (1973) Synoptic climatology: methods and applications. Methuen \& $\mathrm{Co}$, London

Bauer F, Hess P. Nagel H (1944) Kalender der Grosswetterlagen Europas, 1881-1939. Deutsches Wetterdienst, Bad Homburg

Bergeron T (1930) Richtlinien einer dynamischen Klimatologie. Meteorol Zeitschr 47:246-262

Borchert JR (1950) The climate of the Central North. American grassland. Ann Ass Am Geogr 40:1-39

Box GEP, Wetz J (1973) Criteria for judging adequacy of estimation by an approximating response function. University of Wisconsin Statistics Department Technical Report, \#9, Madison

Bryson RA (1966) Air masses, streamlines, and the boreal forest. Geogr Bull 8:228-269

CDC (Centers for Disease Control) (1995) Heat related mortality-Chicago, July 1995. Morb Mortal Wkly Rep 44: $577-579$

Corcoran WT (1982) Moisture stress, mid-tropospheric pressure patterns, and the forest/grassland transition in the South Central States. Phys Geogr 3:148-159

Crowe PR (1971) Concepts in climatology. St. Martin's Press, New York

Davis RE, Kalkstein LS (1990) Using a spatial synoptic climatological classification to assess changes in atmospheric pollution concentrations. Phys Geogr 11:320-342

El-Kadi AKA, Smithson PA (1992) Atmospheric classifications and synoptic climatology. Progr Phys Geogr 16: $432-455$

Greene JS (1994) Examination of precipitation variability and validation of satellite-based rainfall algorithm using a new spatial synoptic classification. PhD dissertation, University of Delaware, Newark

Harmon JR (1987) Mean monthly North American anticyclone frequencies, 1950-79. Mon Wea Rev 115:2840-2848

Harmon JR (1991) Synoptic climatology of the westerlies: process and patterns. Association of American Geographers, Washington, DC

Hsu SA (1988) Coastal meteorology. Academic Press, San Diego

IPCC (Intergovernmental Panel on Climate Change) (1996) 
Climate change 1995; impacts, adaptations, and mitigation of climate change: scientific-technical analysis. Cambridge University Press, ruw York

James M (1985) Classification algorithms. John Wiley and Sons, New York

Kalkstein LS (1972) Spatial and temporal climatic variations along the northern Gulf Coast by means of air mass analysıs. MSc thesis, Louisiana State University, Baton Rouge

Kalkstein LS (1991) A new approach to evaluate the impact of climate upon human mortality. Environ Health Perspect $96: 145-150$

Kalkstein LS (1995) Lessons from a very hot summer. Lancet 346:857-859

Kalkstein LS, Barthel CD, Greene JS, Nichols MC (1996) A new spatial synoptic classification: application to air mass analysis. Int $\mathrm{J}$ Climatol 16(8):1-22

Kalkstein LS, Tan G, Skindlov JA (1987) An evaluation of three clustering procedures for use in synoptic climatological classification. J Clim Appl Meteor 26:717-730

Kalkstein LS, Valimont KM (1986) An evaluation of summer discomfort in the United States using a relative climatological index. Bull Am Meteorol Soc 67:842-848

Editor: V. Meentemeyer, Athens, Georgia, USA
Klecka WR (1980) Discriminant analysis. Sage University Press, Newbury Park, C.A

McMichael AJ, Haines A. Slooff R, Kovats S (eds) (1996) Climate change and human health. WHONMO/UNEP Geneva

Muller RA (1977) A synoptic climatology for environmental baseline analysis. New Orleans. J Clım Appl Meteorol 24 293-301

Muller RA, Jackson A (1985) Estimates of climatic air quality at Shreveport, Louisiana. J Clim Appl Meteor 24:293-301

NCHS (National Center for Health Statistics) (1978) Standardized micro-data tape transcripts. Department of Health, Education and Welfare, Washington, DC

Schwartz MD (1991) An integrated approach to air mass classification in the North Central United States. Prof Geogr 43:77-91

Wendland WM, Bryson RA (1981) Northern Hemisphere airstream regions. Mon Wea Rev 109:255-270

Wilby R (1993) The influence of variable weather patterns on river quantity and quality regimes. Int $\mathrm{J}$ Climatol 13: $447-459$

Yarnal B (1993) Synoptic climatology in environmental analysis. Belhaven Press, London

Manuscript first received: January 26, 1996

Revised version accepted: May 6, 1996 